\title{
Genetic parameters for hoof disorders and feet and leg conformation traits in Finnish Holstein cows
}

\author{
J. Häggman ${ }^{1}$ and J. Juga \\ Department of Agricultural Sciences, University of Helsinki, FI-00014 Helsinki, Finland
}

\begin{abstract}
Hoof disorders are a major welfare problem in dairy farming and result in considerable costs to the farms. In this study, the data from 24,685 Holstein cows from 1,337 herds between 2003 and 2010 were used to evaluate the correlation between hoof disorders and feet and leg conformation traits using a binomial mixed model for hoof disorders in Finnish Holstein cows. Heritabilities and correlations among the hoof disorders and feet and leg conformation traits were also estimated. Heritability estimates from univariate logistic models for 8 hoof disorders ranged from 0.02 (sole hemorrhage, chronic laminitis, and heel horn erosion) to 0.13 (digital dermatitis). Heritability estimates using the liability scale from the multivariate linear model for the 5 most-common hoof disorders ranged from 0.02 (sole hemorrhage) to 0.11 (corkscrew hoof). Estimates of heritability for feet and leg conformation traits from the multivariate linear model ranged from 0.10 (rear leg rear view) to 0.19 (rear leg side view). Genetic correlations among hoof disorders ranged from -0.36 to 0.57 , and genetic correlations among feet and leg conformation traits ranged from -0.30 to 0.83 . The genetic correlations between hoof disorders and feet and leg conformation traits ranged from -0.51 to 0.45 . Most of the genetic correlations between various hoof disorders and feet and leg conformaStion traits were low and most were nonsignificantly different from zero. This indicates that indirect selection for better hoof health using feet and leg conformation traits as indicator traits is not efficient in the Finnish Holstein breed. Key words: hoof disorder, dairy cow, genetic correlation, heritability
\end{abstract}

\section{INTRODUCTION}

Hoof and leg disorders are a major welfare problem in dairy farming, often causing pain and lameness in cows (Alban, 1995; Enting et al., 1997; van der Waaij

Received November 1, 2012.

Accepted January 23, 2013.

${ }^{1}$ Corresponding author: johanna.haggman@helsinki.fi et al., 2005). Hoof disorders are also associated with considerable costs and have been identified as the third most costly disease in dairy farming after mastitis and infertility (Baggott, 1982; Kossaibati and Esslemont, 1996; Enting et al., 1997). The effect of environmental factors on hoof health is high and due to the low heritabilities of hoof disorders, the improvement of hoof health in the short-term can be achieved most easily by improving environmental factors (Van der Waaij et al., 2005). However, in the long-term, direct or indirect genetic selection or both may be the best means of improving hoof health. Indirect selection for feet and leg conformation traits, which are correlated with hoof disorders, can be used while breeding for better hoof health if the correlations between hoof health traits and conformation traits are sufficiently strong (Van der Waaij et al., 2005). Because of the higher heritability of feet and leg conformation traits, indirect selection could potentially be used to improve the efficiency of genetic evaluations and allow earlier prediction of breeding values. Indicator traits could also be used together with direct selection to improve the efficiency of genetic selection.

Since October 2008, the selection of dairy bulls and cows in Finland, Denmark, and Sweden has been based on a joint total merit index, the Nordic total merit (NTM) index. The EBV for hoof health is based on the data collected by hoof trimmers. The EBV for hoof health were published for the first time in May 2011 and were included in the NTM in August 2011 (NAV, 2012). The model for hoof health is a joint linear multiple-trait animal model, which includes 7 hoof disorders or groups of hoof disorders from the 3 first lactations (NAV, 2012).

Hoof health evaluations currently use estimates of Danish and Swedish parameters. Because genetic parameters are population specific, it is important to estimate genetic parameters for these traits also in Finland to check their compatibility with the values used by the Nordic Cattle Genetic Evaluation (NAV). Usually, linear mixed models have been used to estimate genetic parameters for hoof disorders (e.g., Laursen et al., 2009). Phenotypic observation of the trait is binary; binomial models could yield better estimates. The advan- 
tage of using a threshold model in the genetic analysis increases when the incidence of the binary trait and its heritability decreases (Mrode, 2005). Both a sire model (van der Waaij et al., 2005; Laursen et al., 2009) and an animal model (Koenig et al., 2005; Johansson et al., 2011; Häggman et al., 2012) have been used in genetic analysis of hoof disorders. In the current study, the animal model was chosen to use all available genetic relationships and because a similar analysis of hoof health has already been done with a sire model for Finnish Holstein cows (Pekkala, 2010). An animal model is also more robust to selection bias and produces parameter estimates with lower standard errors than a sire model (Henderson, 1984; Hudson and Schaeffer, 1984). Aims of the study were to evaluate the genetic correlation between hoof disorders and feet and leg conformation traits using a binomial mixed model for hoof disorders in Finnish Holstein cows and to estimate heritabilities and genetic correlations among the hoof disorders and feet and leg conformation traits.

\section{MATERIALS AND METHODS}

\section{Data}

The full national data set consisted of 94,449 hooftrimming observations of 29,624 Finnish Holstein cows made by hoof trimmers between 2003 and 2010. The hoof health data were merged with feet and leg conformation data recorded by breeding advisors from Faba (Hollola, Finland) between 2000 and 2010.

\section{Hoof Health Data and Feet and Leg Conformation Data}

All hoof disorders were recorded as 0 (absence) or 1 (disorder). The original data included 8 different hoof disorders, namely sole hemorrhage (SH), interdigital dermatitis (ID), sole ulcer (SU), white-line separation (WLS), heel horn erosion $(\mathbf{H H})$, corkscrew hoof (CSH), chronic laminitis (CL), and digital dermatitis (DD). The 5 most common hoof disorders were included in the estimation of genetic correlations.

The definitions of hoof disorders are similar to those of other countries, except for that of CSH, which is usually recorded if the twist is over $180^{\circ}$; but in Finland, all twists over $90^{\circ}$ are recorded. Some differences exist in the scale of recording disorders; in Finland, the scoring is done by using a $0 / 1$ scale (except dermatitis) and in Sweden and Denmark, using a 0/1/2 scale. A more thorough description of hoof health data collection is presented in Häggman et al. (2012).

To evaluate only routine trimmings in the final data, duplicate records for a cow on the same trimming day and records for a cow within $7 \mathrm{~d}$ from each other were removed (18,058 observations). Records for herd trimming days with less than 5 trimmed cows were omitted (11,190 observations). Trimming observations before the age of 21 mo or after 165 mo were also excluded (49 observations).

The original data included 6 different feet and leg conformation traits, namely rear leg rear view (RLRV), rear leg side view (RLSV), hock quality (HQ), bone structure (BS), foot angle (FA), and fetlock angle (FEA). The 5 first conformation traits mentioned are included in the NAV, whereas FEA is a national trait recorded only in Finland. Breeding advisors evaluate conformation traits using a linear scale from 1 to 9 . Only the first feet and leg conformation trait evaluation was included in the statistical analyses.

\section{Final Data}

The percentages of hoof disorders in the final data are shown in Table 1. The final data with records of hoof health and feet and leg conformation traits consisted of 65,152 observations from 24,685 Holstein cows in 1,337 herds. Most of the cows had been trimmed 1 to 2 times per year. The average number of trimmed cows per herd was 18 and there were 5 to 311 hoof trimming observations per herd. The cows descended from 1,311 sires with 1 to 1,365 daughters, the average number of daughters per sire being 17. Some cows with hoof-trimming records were missing observations for feet and leg conformation traits. Differences were present in the number of observations for different feet and leg conformation traits because some of the traits have been added later to genetic evaluation when conformation scoring was standardized with other countries. The data for feet and leg conformation traits are summarized in Table 2. Only the records for pure Holsteins were used, and pedigrees were traced back 5 generations.

\section{Statistical Analyses}

The binary hoof health data and the linearly scored feet and leg conformation data were analyzed using a restricted maximum likelihood (REML) animal model and the ASReml 3.0 software package (Gilmour et al., 2009). Because hoof health is a binary trait, the residuals are not normally distributed, which is why a linear logistic model with mixed effects (Knuiman and Laird, 1990) was applied as in Häggman et al. (2012). The heritability estimates for different hoof disorders and for different feet and leg conformation traits were derived from multivariate analysis with a linear mixed model. Because of computational restrictions, it was 
Table 1. Prevalence of hoof disorders

\begin{tabular}{lc}
\hline & Prevalence, \\
Disorder & $\%$ \\
\hline Sole hemorrhage & 20.68 \\
Chronic laminitis & 1.37 \\
White-line separation & 10.64 \\
Sole ulcer & 6.11 \\
Interdigital dermatitis & 0.70 \\
Heel horn erosion & 4.71 \\
Digital dermatitis & 0.16 \\
Corkscrew hoof & 4.36 \\
Other hoof disorder $_{\text {Preventive treatment }=\text { healthy }}{ }^{1}$ & 0.89 \\
One or more hoof disorders & 50.38 \\
\hline
\end{tabular}

${ }^{1}$ The cow was trimmed and no disorders found.

not possible to fit a logistic model in the multivariate analyses for more than one trait. The heritabilities for hoof disorders were also estimated with univariate binomial logistic models. Genetic and phenotypic correlations between hoof disorders and feet and leg conformation traits were obtained from multivariate mixed model analysis between one binary hoof disorder and 2 quantitative feet and leg conformation traits at a time. Genetic and phenotypic correlations among hoof disorders and among feet and leg conformation traits were estimated with a multivariate linear model for 4 traits at a time.

The logistic regression model used for binary hoof disorders was as follows:

$$
\begin{aligned}
\operatorname{logit}\left(p_{i j k l m n}\right) & =\mu+Y S_{i}+A G_{j}+L A_{k} \\
+h e_{l} & +h t_{m}+a n_{n}+p e_{n},
\end{aligned}
$$

where

$$
\operatorname{logit}\left(p_{i j k l m n}\right)=\ln \left[\frac{p_{i j k l m n}}{1-p_{i j k l m n}}\right]=\ln \left[\frac{P\left(Y_{i j k l m n}=1\right)}{1-P\left(Y_{i j k l m n}=1\right)}\right],
$$

and $p_{i j k l m n}=P\left(Y_{i j k l m n}=1\right)$ denotes the probability of cow $n$ having a hoof disorder in year-season $i$, age at the time of trimming $j$, lactation stage $k$, herd $l$, hoof trimmer $m$, and permanent environment $n$; $Y_{i j k l m n}$ is a bi- nary hoof-trimming observation. Here, $\mu$ is the overall mean, $Y S_{i}$ is the fixed effect of year-season $(i=1$ to 32 ; there are 571 to 3,690 observations per class, and the season is defined as $1=$ December to February, $2=$ March to May, $3=$ June to August, and $4=$ September to November), $A G_{j}$ is the fixed effect of the age at the time of trimming in months $(j=21$ to $165 ; 3$ to 1,531 observations per class), $L A_{k}$ is the $k$ th lactation stage at the time of trimming ( $k=1$ to 8 , where $1=1$ to $60 \mathrm{~d}$, $2=61$ to $120 \mathrm{~d}, 3=121$ to $180 \mathrm{~d}, 4=181$ to $240 \mathrm{~d}, 5$ $=241$ to $300 \mathrm{~d}, 6=301$ to $360 \mathrm{~d}, 7=361$ to $430 \mathrm{~d}$, and $8=$ over $430 \mathrm{~d} ; 3,178$ to 11,510 observations per class), $h e_{l}$ is the random herd effect $[l=1$ to 1,337 ; $h e \sim \mathrm{MVN}$ $\left(\mathbf{0}, \mathbf{I} \sigma_{h e}^{2}\right)$, where MVN = multivariate normal, $\sigma_{h e}^{2}$ is the herd variance and $\mathbf{I}$ is the identity matrix; this is so also in all following formulas], $h t_{m}$ is the random hoof trimmer effect $\left[m=1\right.$ to $80 ; H T \sim \operatorname{MVN}\left(\mathbf{0}, \mathbf{I} \sigma_{h t}^{2}\right)$, where $\sigma_{h t}^{2}$ is the hoof trimmer variance], $a n_{n}$ is the random animal effect $\left[\right.$ an $\sim \operatorname{MVN}\left(\mathbf{0}, \mathbf{A} \sigma_{a}^{2}\right)$, where $\mathbf{A}$ is the additive genetic relationship matrix among animals and $\sigma_{a}^{2}$ is the additive genetic variance], and $p e_{n}$ is the random animal permanent environmental effect $\left[p e \sim \operatorname{MVN}\left(\mathbf{0}, \mathbf{I} \sigma_{p e}^{2}\right)\right.$, where $\sigma_{p e}^{2}$ is the permanent environmental variance]. The residual variance for the binary hoof health trait was fixed to the underlying liability scale at $\sigma_{e 1}^{2}=1.0$. The heritabilities were calculated by using the variance of logit link function. This implies the correction of the residual variance by $\pi^{2} / 3$, which is the variance of standard logistic distribution (Fahrmeir and Tutz, 1994).

Multivariate Analysis for Hoof Disorders. The effects used were the same as for logistic model 1 for the univariate analysis, with the addition of a random error term $(e)$. The distributions of $a n_{n}, p e_{n}, h e_{l}, h t_{m}$, and $e_{i j k l m n}$ were assumed to be multivariate normal with zero means. The variance-covariance structure for all 4 animal effects were defined as $\mathbf{G}=\mathbf{G}_{0} \otimes \mathbf{A}$, where $\mathbf{G}_{0}$ includes the additive genetic variances and additive genetic covariances between animal effects $\left(a n_{n}\right), \otimes$ denotes the Kronecker product, and $\mathbf{A}$ is the additive genetic relationship matrix. The variance-covariance structures for all 4 permanent environment effects were defined as $\mathbf{P}=\mathbf{P}_{0} \otimes \mathbf{I}$, where $\mathbf{P}_{0}$ includes the variances

Table 2. Number of cows in the final data that had conformation traits, and means and standard deviations of the traits

\begin{tabular}{lclccc}
\hline Trait & Cows, no. & Scale & Mean & SD & Optimum \\
\hline Hock quality & 3,745 & $1=$ filled; $9=$ dry & 4.98 & 1.33 & 9 \\
Fetlock angle & 7,627 & $1=$ sickled; 9 = straight & 5.46 & 1.29 & 5 \\
Rear leg side view & 7,627 & $1=$ straight; $9=$ sickled & 4.63 & 1.31 & 5 \\
Rear leg rear view & 7,439 & $1=$ toes out; $9=$ parallel bow-legged & 5.35 & 1.43 & 8 \\
Foot angle & 7,396 & $1=$ low; $9=$ steep & 4.64 & 1.34 & 6.5 \\
Bone structure & 3,745 & $1=$ coarse; $9=$ fine/thin & 5.48 & 1.21 & 8 \\
\hline
\end{tabular}


due to permanent environment effects and the covariances between permanent environment effects $\left(p e_{n}\right)$ for different traits. The variance-covariance structures for all 4 herd effects were defined as $\mathbf{H}=\mathbf{H}_{0} \otimes \mathbf{I}$, where $\mathbf{H}_{0}$ includes the variances due to herd effects and the covariances between herd effects $\left(h e_{l}\right)$ for different traits. The variance-covariance structures for all 4 hoof trimmer effects were defined as $\mathbf{T}=\mathbf{T}_{0} \otimes \mathbf{I}$, where $\mathbf{T}_{0}$ includes the variances due to hoof trimmer effects and the covariances between hoof trimmer effects $\left(h t_{m}\right)$ for different traits. The variance-covariance structures for all 4 residual effects were defined as $\mathbf{R}=\mathbf{R}_{0} \otimes \mathbf{I}$, where $\mathbf{R}_{0}$ includes the variances due to residual effects and the covariances between residual effects $\left(e_{i j k l m n}\right)$ for different traits. To facilitate comparison with other studies, the heritabilities from the linear model on the observed scale were transformed to the underlying liability scale by using the formula of Gilmour et al. (2001) in a similar way as in Häggman et al. (2012).

The linear mixed model used for each conformation trait was as follows:

$$
\begin{gathered}
Y_{i j k l m n}=\mu+Y S_{i}+A G_{j}+L A_{k} \\
+h e_{l}+c f_{m}+a n_{n}+e_{i j k l m n}
\end{gathered}
$$

where $Y_{i j k l m n}$ is the observation of conformation trait, $\mu$ is the overall mean, $Y S_{i}$ is the fixed effect of year-season ( $i=1$ to $40 ; 1$ to 1,449 observations per class and the season is defined as in model 1$), A G_{j}$ is the fixed effect of the age at the time of observation in months $(j=21$ to $147 ; 1$ to 1,567 observations per class), $L A_{k}$ is the $k$ th lactation stage at the time of observation $(k=1$ to 7 , where $1=1$ to $60 \mathrm{~d}, 2=61$ to $120 \mathrm{~d}, 3=121$ to $180 \mathrm{~d}$, $4=181$ to $240 \mathrm{~d}, 5=241$ to $300 \mathrm{~d}, 6=301$ to $360 \mathrm{~d}$, and $7=361$ to $430 \mathrm{~d} ; 247$ to 7,882 observations per class), $h e_{l}$ is the random herd effect $[l=1$ to 1,337 ; he $\sim \operatorname{MVN}\left(\mathbf{0}, \mathbf{I} \sigma_{h e}^{2}\right)$, where $\sigma_{h e}^{2}$ is the herd variance], $c f_{m}$ is the random classifier effect $[m=1$ to $92 ; c f \sim \mathrm{MVN}$ $\left(\mathbf{0}, \mathbf{I} \sigma_{c f}^{2}\right)$, where $\sigma_{c f}^{2}$ is the classifier variance], $a n_{n}$ is the random animal effect $\left[a n \sim \mathrm{MVN}\left(\mathbf{0}, \mathbf{A} \sigma_{a}^{2}\right)\right.$, where $\mathbf{A}$ is the additive genetic relationship matrix among animals and $\sigma_{a}^{2}$ is the additive genetic variance], and $e_{i j k l m n}$ is the random residual $\left[e \sim \operatorname{MVN}\left(\mathbf{0}, \mathbf{I} \sigma_{e}^{2}\right)\right.$, where $\sigma_{e}^{2}$ is the residual variance].

Multivariate Analysis for Conformation Traits. The distributions of $a n_{n}, c f_{m}, h e_{l}$, and $e_{i j k l m n}$ were assumed to be multivariate normal with zero means. The variance-covariance structure for $a n_{n}, h e_{l}$, and $e_{i j k l m n}$ were defined in similar way as in multivariate analysis among hoof disorders. The variance-covariance structures for all 4 classifier effects were defined as $\mathbf{C}=$
$\mathbf{C}_{0} \otimes \mathbf{I}$, where $\mathbf{C}_{0}$ includes the variances due to classifier effects and the covariances between classifier effects $\left(c f_{m}\right)$ for different traits.

Correlations Between Hoof Disorder and 2 Conformation Traits At a Time. Models 1 and 2 were used for multivariate analysis. The distributions of $a n_{n}, p e_{n}, h e_{l}, h t_{m}, c f_{m}$, and $e_{i j k l m n}$ were assumed to be multivariate normal with zero means. Variancecovariance structures for $a n_{n}$ and $e_{i j k l m n}$ were defined in similar way as in multivariate analysis among hoof disorders. The covariances between $p e_{n}, h e_{l}, h t_{m}$, and $c f_{m}$ were assumed to be zero.

\section{RESULTS AND DISCUSSION}

\section{Estimates of Heritability}

Hoof Disorders. Estimates of the heritability from univariate logistic models for 8 hoof disorders ranged from 0.02 to 0.13 (Table 3). Genetic and phenotypic correlation analyses between the 5 most common hoof disorders generated another set of heritability estimates for hoof disorders at an observed scale. Heritability estimates from the multivariate linear model ranged from 0.01 to 0.02 . When transformed to the underlying liability scale, the heritability estimates ranged from 0.02 to 0.11 (Table 4). Results indicate that most of the hoof disorders are heritable, but the estimated heritabilities are low, which is in agreement with many previous studies (e.g., van der Waaij et al., 2005; Buch et al., 2011; Johansson et al., 2011).

The low heritabilities might be due to the low prevalence of hoof disorders and a large environmental influence. Johansson et al. (2011) presented a hoof health index for Holstein and Red dairy cattle, which was included in NTM, and is routinely run in the joint genetic evaluation for Finland, Denmark, and Sweden. The estimated heritabilities for WLS and CSH from the multivariate linear model were similar to those used in the Nordic hoof health index for the Holstein breed. The estimated heritabilities from the multivariate linear model for SH, SU, and $\mathrm{HH}$ were a little lower than those used in the Nordic hoof health index for the Holstein breed. The estimated heritabilities from the multivariate linear model were lower than those from logistic models. When the heritability estimates from the linear multivariate model were transformed to the underlying liability scale, the estimates were close to those from logistic models.

Feet and Leg Conformation Traits. Estimates of heritability for feet and leg conformation traits from the multivariate linear model (Table 5) ranged from 0.10 (RLRV) to 0.19 (RLSV). The estimated heritabilities for RLSV, RLRV, HQ, and FA are in accordance 
Table 3. Estimates of heritability $\left(\mathrm{h}^{2}\right)$ and additive $\left(\sigma_{a}^{2}\right)$, permanent environmental $\left(\sigma_{p e}^{2}\right)$, herd $\left(\sigma_{h e}^{2}\right)$, and hoof trimmer $\left(\sigma_{h t}^{2}\right)$ variances in different hoof disorders in the logistic univariate model

\begin{tabular}{lccccc}
\hline Hoof disorder & $\mathrm{h}^{2} \pm \mathrm{SE}$ & $\sigma_{a}^{2}$ & $\sigma_{p e}^{2}$ & $\sigma_{h e}^{2}$ & $\sigma_{h t}^{2}$ \\
\hline Sole hemorrhage & $0.02 \pm 0.01$ & 0.09 & 0.06 & 0.34 & 1.25 \\
Chronic laminitis & $0.02 \pm 0.04$ & 0.17 & 1.72 & 0.53 & 2.38 \\
White-line separation & $0.04 \pm 0.02$ & 0.19 & 0.46 & 0.63 & 0.54 \\
Sole ulcer & $0.08 \pm 0.03$ & 0.44 & 0.76 & 0.37 & 0.38 \\
Interdigital dermatitis & $0.03 \pm 0.04$ & 0.23 & 1.47 & 1.78 & 0.36 \\
Heel horn erosion & $0.02 \pm 0.01$ & 0.13 & 0.54 & 2.43 & 0.93 \\
Digital dermatitis & $0.13 \pm 0.05$ & 0.94 & 0.00 & 2.10 & 1.04 \\
Corkscrew hoof & $0.09 \pm 0.03$ & 0.52 & 0.87 & 0.77 & 0.49 \\
\hline
\end{tabular}

with previous studies (Pérez-Cabal and Alenda, 2002; Boelling et al., 2007). Boelling et al. (2007) estimated a heritability for BS of 0.24 and Uggla et al. (2008) of 0.23 , which are slightly higher than the estimate in the current study $(0.17 \pm 0.03)$. Uggla et al. (2008) estimated the heritability for FA to be 0.16 , which is clearly higher than our estimate $(0.09 \pm 0.02)$.

\section{Genetic and Phenotypic Correlations}

Among Hoof Disorders. The genetic correlations among the 5 most common hoof disorders were mostly low to moderate, indicating that these disorders have largely different genetic backgrounds. Genetic correlations among hoof disorders ranged from -0.36 to 0.57 (Table 4). The highest genetic correlation was found between CSH and SU and the lowest between WLS and HH. Most standard errors of the estimates were high, which might result from the low prevalence of hoof disorders. A large variation exists in the genetic correlations among hoof disorders in the literature. Johansson et al. (2011) reported a genetic correlation of 0.73 between SH and WLS and van der Waaij et al. (2005) noted a genetic correlation of $0.30 \pm 0.21$ between the same traits, which is close to the estimate in the current study $(0.39 \pm 0.12)$. The genetic correlations between $\mathrm{HH}$ and other disorders were negative, but these estimates also had high standard errors and only the correlation between HH and WLS was significantly different from zero. The genetic correlations between WLS and CSH and between SU and CSH were in accordance with estimates reported by Johansson et al. (2011). The correlation between SH and SU was lower than the corresponding estimates found in the literature (Van der Waaij et al., 2005; Buch et al., 2011; Johansson et al., 2011).

Phenotypic correlations among the 5 most common hoof disorders were all low and negative, ranging from -0.24 to -0.06 (Table 4 ). The highest negative phenotypic correlation was observed between WLS and SH and the lowest between CSH and SU and between CSH and HH. Most of the cows in the data had only 1 or 2 hoof disorders within a trimming day, which possibly explains the negative phenotypic correlations between different hoof disorders. A reason could be that hoof trimmers only marked the worst disorder. The phenotypic correlations among hoof disorders were lower than the corresponding genetic correlations, as in many previous studies (van der Waaij et al., 2005; Johansson et al., 2011).

Among Feet and Leg Conformation Traits. Genetic correlations among feet and leg conformation traits ranged from -0.30 to 0.83 (Table 6 ). The highest genetic correlation was seen between $\mathrm{HQ}$ and $\mathrm{BS}$ and the lowest between FEA and RLSV. Genetic correlations among feet and leg conformation traits were mostly low to moderate, in accordance with earlier studies (Boelling et al., 2001; Uggla et al., 2008). The correlation between HQ and BS was high and positive $(0.83 \pm 0.07)$, which is also in accord with previous research (Boelling et al., 2001; Uggla et al., 2008). The correlation between FA and RLSV was small and nega-

Table 4. Heritability under liability scale (diagonal), genetic (above diagonal), and phenotypic (below diagonal) correlations among hoof disorders and their standard errors in the multivariate analysis

\begin{tabular}{lcccrr}
\hline Item & $\begin{array}{c}\text { Sole } \\
\text { hemorrhage }\end{array}$ & $\begin{array}{c}\text { White-line } \\
\text { separation }\end{array}$ & $\begin{array}{c}\text { Sole } \\
\text { ulcer }\end{array}$ & $\begin{array}{c}\text { Heel horn } \\
\text { erosion }\end{array}$ & $\begin{array}{c}\text { Corkscrew } \\
\text { hoof }\end{array}$ \\
\hline Sole hemorrhage & 0.02 & $0.39 \pm 0.12$ & $0.38 \pm 0.15$ & $-0.07 \pm 0.20$ & $0.00 \pm 0.15$ \\
White-line separation & $-0.24 \pm 0.01$ & 0.03 & $0.31 \pm 0.13$ & $-0.36 \pm 0.12$ & $0.20 \pm 0.10$ \\
Sole ulcer & $-0.18 \pm 0.01$ & $-0.12 \pm 0.00$ & 0.07 & $-0.05 \pm 0.21$ & $0.57 \pm 0.14$ \\
Heel horn erosion & $-0.13 \pm 0.01$ & $-0.10 \pm 0.01$ & $-0.07 \pm 0.01$ & 0.03 & $-0.04 \pm 0.23$ \\
Corkscrew hoof & $-0.13 \pm 0.01$ & $-0.09 \pm 0.01$ & $-0.06 \pm 0.01$ & $-0.06 \pm 0.00$ & 0.11 \\
\hline
\end{tabular}


Table 5. Estimates of heritability $\left(\mathrm{h}^{2}\right)$ and additive $\left(\sigma_{a}^{2}\right)$, residual $\left(\sigma_{e}^{2}\right)$, herd $\left(\sigma_{h e}^{2}\right)$, and classifier $\left(\sigma_{c f}^{2}\right)$ variances in feet and leg conformation traits in the multivariate analysis

\begin{tabular}{lccccc}
\hline Trait & $\mathrm{h}^{2} \pm \mathrm{SE}$ & $\sigma_{a}^{2}$ & $\sigma_{e}^{2}$ & $\sigma_{h e}^{2}$ & $\sigma_{c f}^{2}$ \\
\hline Hock quality & $0.18 \pm 0.04$ & 0.30 & 1.27 & 0.14 & 0.10 \\
Fetlock angle & $0.16 \pm 0.03$ & 0.25 & 1.10 & 0.12 & 0.10 \\
Rear leg side view & $0.19 \pm 0.03$ & 0.32 & 1.21 & 0.06 & 0.12 \\
Rear leg rear view & $0.10 \pm 0.02$ & 0.19 & 1.46 & 0.10 & 0.10 \\
Foot angle & $0.09 \pm 0.02$ & 0.16 & 1.39 & 0.13 & 0.17 \\
Bone structure & $0.17 \pm 0.03$ & 0.25 & 1.00 & 0.06 & 0.15 \\
\hline
\end{tabular}

tive and weaker than the corresponding correlations in the literature (Boelling et al., 2001; van der Waaij et al., 2005; Uggla et al., 2008). The correlations among FEA and other feet and leg conformation traits ranged from moderately negative to moderately positive; FEA is a national trait and no references were found in the literature.

Phenotypic correlations among feet and leg conformation traits ranged from -0.12 to 0.50 (Table 6). The highest phenotypic correlation was observed between HQ and BS and the lowest between FEA and RLSV.

Between Hoof Disorders and Conformation Traits. The genetic correlations between hoof disorders and feet and leg conformation traits ranged from -0.51 to 0.45 (Table 7 ). Most standard errors of the estimates were so high that the genetic correlations are inconclusive. High standard errors might be due to the low prevalence of hoof disorders and small amount of data specifically in conformation traits. The genetic correlations were mostly low to moderate and most were nonsignificantly different from zero, in accordance with other studies (van der Waaij et al., 2005; Uggla et al., 2008). Strong negative genetic correlations were found between SU and FA and between CSH and FA. The strong negative correlation between SU and FA $(-0.51$ \pm 0.12 ) suggests that cows with steeper foot angles are less susceptible to sole ulcer. Uggla et al. (2008) reported a genetic correlation of $-0.03 \pm 0.08$ between SU and FA and Koenig et al. (2005) noted a genetic correlation of -0.29 between the same traits. No reference was found in the literature for genetic correlations between $\mathrm{CSH}$ and feet and leg conformation traits. The genetic correlation between FA and $\mathrm{HH}$ was moderate and positive $(0.45 \pm 0.19)$, suggesting that cows with steeper foot angles are more susceptible to heel horn erosion. Uggla et al. (2008) reported a lower genetic correlation between FA and HH $(0.07 \pm 0.08)$. Because of the low correlations between hoof disorders and feet and leg conformation traits and because many of these correlations were nonsignificantly different from zero, it seems that indirect selection for better hoof health using feet and leg conformation traits as indicator traits is not efficient in the Finnish Holstein breed. Using feet and leg conformation traits as indicator traits together with hoof trimming information could increase the accuracy of breeding values for hoof health somewhat in genetic evaluation especially for bulls with only few progeny records. These assumptions were checked with simple selection index calculations using the estimated genetic parameters to illustrate the approximate gain in the accuracy of selection for SU by using FA or RLSV as indicator traits. Results of these illustrations (not published) showed that the increase in the accuracy was negligible when using indirect selection together with direct selection. When only indirect selection (FA or RLSV) was used the accuracy was low. Currently NAV uses genomic information for the prediction of breeding values, where the EBV of reference bulls are based on large numbers of daughters and, hence, the gain in accuracy due to indirect information is less important. Most of the genetic parameters were similar to the values used by NAV, which are based on Danish and Swedish data. Based on these results, no need exists for NAV to include conformation traits into the

Table 6. Genetic (above diagonal) and phenotypic (below diagonal) correlations among feet and leg conformation traits and their standard errors

\begin{tabular}{|c|c|c|c|c|c|c|}
\hline Item & $\begin{array}{l}\text { Hock } \\
\text { quality }\end{array}$ & $\begin{array}{c}\text { Fetlock } \\
\text { angle }\end{array}$ & $\begin{array}{l}\text { Rear leg } \\
\text { side view }\end{array}$ & $\begin{array}{l}\text { Rear leg } \\
\text { rear view }\end{array}$ & $\begin{array}{l}\text { Foot } \\
\text { angle }\end{array}$ & $\begin{array}{c}\text { Bone } \\
\text { structure }\end{array}$ \\
\hline Hock quality & & $-0.03 \pm 0.14$ & $0.40 \pm 0.12$ & $0.31 \pm 0.13$ & $0.20 \pm 0.16$ & $0.83 \pm 0.07$ \\
\hline Fetlock angle & $-0.01 \pm 0.02$ & & $-0.30 \pm 0.10$ & $0.27 \pm 0.12$ & $0.37 \pm 0.12$ & $-0.03 \pm 0.14$ \\
\hline Rear leg rear view & $0.10 \pm 0.02$ & $0.06 \pm 0.02$ & $-0.04 \pm 0.02$ & & $-0.05 \pm 0.15$ & $0.12 \pm 0.15$ \\
\hline Foot angle & $0.01 \pm 0.02$ & $0.20 \pm 0.02$ & $0.02 \pm 0.02$ & $-0.03 \pm 0.02$ & & $0.06 \pm 0.07$ \\
\hline Bone structure & $0.50 \pm 0.02$ & $0.01 \pm 0.02$ & $0.01 \pm 0.02$ & $0.12 \pm 0.02$ & $0.03 \pm 0.05$ & \\
\hline
\end{tabular}


Table 7. Genetic correlations between hoof disorders and feet and leg conformation traits and their standard errors in the multivariate analysis

\begin{tabular}{lccrrr}
\hline Trait & $\begin{array}{c}\text { Sole } \\
\text { hemorrhage }\end{array}$ & $\begin{array}{c}\text { White-line } \\
\text { separation }\end{array}$ & \multicolumn{1}{c}{$\begin{array}{c}\text { Sole } \\
\text { ulcer }\end{array}$} & $\begin{array}{c}\text { Heel horn } \\
\text { erosion }\end{array}$ & $\begin{array}{c}\text { Corkscrew } \\
\text { hoof }\end{array}$ \\
\hline Hock quality & $0.06 \pm 0.13$ & $-0.23 \pm 0.09^{*}$ & $0.29 \pm 0.15$ & $0.19 \pm 0.22$ & $0.06 \pm 0.15$ \\
Fetlock angle & $-0.07 \pm 0.10$ & $0.04 \pm 0.13$ & $-0.18 \pm 0.10$ & $0.07 \pm 0.18$ & $-0.12 \pm 0.12$ \\
Rear leg side view & $0.17 \pm 0.04^{*}$ & $0.04 \pm 0.12$ & $0.19 \pm 0.10$ & $-0.22 \pm 0.17$ & $-0.09 \pm 0.11$ \\
Rear leg rear view & $0.04 \pm 0.06$ & $0.04 \pm 0.14$ & $0.31 \pm 0.12^{*}$ & $-0.29 \pm 0.18$ & $0.33 \pm 0.12^{*}$ \\
Foot angle & $-0.08 \pm 0.06$ & $-0.24 \pm 0.11^{*}$ & $-0.51 \pm 0.12^{*}$ & $0.45 \pm 0.19^{*}$ & $-0.50 \pm 0.13^{*}$ \\
Bone structure & $-0.21 \pm 0.09^{*}$ & $-0.26 \pm 0.15$ & $-0.04 \pm 0.14$ & $-0.10 \pm 0.21$ & $0.07 \pm 0.15$ \\
\hline
\end{tabular}

*The estimate was significantly different from zero $(P<0.05)$.

hoof health index and the current genetic parameters are also suitable for Finnish Holstein cows.

The phenotypic correlations between hoof disorders and feet and leg conformation traits were all close to zero and ranged between -0.06 and 0.07 , as in many previous studies (Van der Waaij et al., 2005; Laursen et al., 2009).

\section{CONCLUSIONS}

The heritability estimates for the various hoof disorders using the binomial logistic model and the multivariate linear model were low. Moreover, the heritability estimates for the feet and leg conformation traits were quite low. Most of the genetic correlations between various hoof disorders and feet and leg conformation traits were low and most were nonsignificantly different from zero. This indicates that indirect selection for better hoof health using feet and leg conformation traits as indicator traits is not efficient in the Finnish Holstein breed. The results highlight the importance of national recording of hoof health traits.

\section{ACKNOWLEDGMENTS}

This work was supported by the Finnish Ministry of Agriculture and Forestry (Helsinki, Finland) and the Aino and August Johannes Tiura Foundation (Helsinki, Finland). The data were provided by Faba (Hollola, Finland).

\section{REFERENCES}

Alban, L. 1995. Lameness in Danish dairy cows: Frequency and possible risk factors. Prev. Vet. Med. 22:213-225.

Baggott, D. G. 1982. Losses due to lameness caused by physical contact with buildings. Technical J. Farm Buildings Assoc. 30:12-15.

Boelling, D., A. Fogh, and U. Sander Nielsen. 2007. Locomotion as a new trait: First results from Denmark. Interbull Bull. 37:175-178.

Boelling, D., P. Madsen, and J. Jensen. 2001. Genetic parameters of foot and leg traits in future AI bulls II: Correlation to body conformation traits in daughters. Acta Agric. Scand. A Anim. Sci. 51:122-128.

Buch, L. H., A. C. Sørensen, J. Lassen, P. Berg, J. Å. Eriksson, J. H. Jakobsen, and M. K. Sørensen. 2011. Hygiene-related and feedrelated hoof diseases show different patterns of genetic correlations to clinical mastitis and female fertility. J. Dairy Sci. 94:1540-1551.
Enting, H., D. Kooij, A. A. Dijkhuizen, R. B. M. Huirne, and E. N. Noordhuizen-Stassen. 1997. Economic losses due to clinical lameness in dairy cattle. Livest. Prod. Sci. 49:259-267.

Fahrmeir, L., and G. Tutz. 1994. Multivariate Statistical Modelling Based on Generalized Linear Models. Springer-Verlag, New York, NY.

Gilmour, A. R., B. R. Cullis, S. J. Welham, and R. Thompson. 2001. ASREML Reference Manual. NSW Agriculture, Orange, Australia.

Gilmour, A. R., B. J. Gogel, B. R. Cullis, and R. Thompson. 2009. ASReml User Guide. Release 3.0. VSN International Ltd., Hemel Hempstead, UK.

Häggman, J., J. Juga, M. J. Sillanpää, and R. Thompson. 2012. Genetic parameters for claw health and feet and leg conformation traits in Finnish Ayrshire cows. J. Anim. Breed. Genet. http:// dx.doi.org/10.1111/j.1439-0388.2012.01007.x.

Henderson, C. R. 1984. Applications of Linear Models in Animal Breeding. L. R. Schaeffer, ed. University of Guelph Press, Guelph, Ontario, Canada.

Hudson, G. F. S., and L. R. Schaeffer. 1984. Monte Carlo comparison of sire evaluation models in populations subject to selection and non-random mating. J. Dairy Sci. 67:1264-1272.

Johansson, K., J.-Å. Eriksson, U. S. Nielsen, J. Pösö, and G. P. Aamand. 2011. Genetic evaluation of claw health in Denmark, Finland and Sweden. Interbull Bull. 44:224-228.

Knuiman, M. W., and N. M. Laird. 1990. Parameter estimation in variance component models for binary response data. Pages 177189 in Advances in Statistical Methods for Genetic Improvement of Livestock. D. Gianola and K. Hammond, ed. Springer-Verlag, Berlin Heidelberg, Germany.

Koenig, S., A. R. Sharifi, H. Wentrot, D. Landmann, M. Eise, and H. Simianer. 2005. Genetic parameters of claw and foot disorders estimated with logistic models. J. Dairy Sci. 88:3316-3325.

Kossaibati, M. A., and R. J. Esslemont. 1996. Wastage in dairy herds. DAISY report number 4. The University of Reading, Reading, UK.

Laursen, M. V., D. Boelling, and T. Mark. 2009. Genetic parameters for claw and leg health, foot and leg conformation, and locomotion in Danish Holsteins. J. Dairy Sci. 92:1770-1777.

Mrode, R. A. 2005. Linear Models for the Prediction of Animal Breeding Values, 2nd Edition. CABI-Publ. Wallingford, UK.

NAV (Nordic Cattle Genetic Evaluation). 2012. Accessed June 20, 2012. http://www.nordicebv.info.

Pekkala, M. 2010. Lypsylehmien sorkkasairauksien sekä jalkarakenneominaisuuksien ja elopainon väliset yhteydet. MSc Thesis. Department of Agricultural Sciences, Univ. of Helsinki, Helsinki, Finland.

Pérez-Cabal, M. A., and R. Alenda. 2002. Genetic relationships between lifetime profit and type traits in Spanish Holstein cows. J. Dairy Sci. 85:3480-3491.

Uggla, E., J. H. Jakobsen, C. Bergsten, J.-Å. Eriksson, and E. Strandberg. 2008. Genetic correlations between claw health and feet and leg conformation traits in Swedish dairy cows. Interbull Bull. 38:91-95.

van der Waaij, E. H., M. Holzhauer, E. Ellen, C. Kamphuis, and G. de Jong. 2005. Genetic parameters for claw disorders in Dutch dairy cattle and correlations with conformation traits. J. Dairy Sci. 88:3672-3678. 